\title{
First identification and multilocus genotyping of Giardia duodenalis in pet chipmunks (Eutamias asiaticus) in Sichuan Province, southwestern China
}

\author{
Lei Deng ${ }^{\dagger}$, Run Luo ${ }^{\dagger}$, Haifeng Liu ${ }^{\dagger}$, Ziyao Zhou, Lingyu Li, Yijun Chai, Leli Yang, Wuyou Wang, Hualin Fu, \\ Zhijun Zhong, Suizhong Cao and Guangneng Peng ${ }^{*}$
}

\begin{abstract}
Background: Giardia duodenalis is a flagellated parasite that causes diarrhea in humans and other animals. Although G. duodenalis is found in companion animals worldwide, information regarding the prevalence and genetic characteristics of $G$. duodenalis in pet chipmunks in China is limited. The present study therefore aimed to investigate the prevalence and genotypes of $G$. duodenalis in pet chipmunks in Sichuan province, southwestern China, as well as to assess zoonotic potential of revealed assemblages.

Results: A total of 279 fecal samples were collected from pet chipmunks in seven pet shops and one breeding facility in Sichuan province, southwestern China. The prevalence of G. duodenalis was 8.6\% (24/279), as determined by nested PCR detection of the beta giardin (bg) gene. Giardia duodenalis assemblages and subtypes were determined using multilocus genotyping of the $b g$, triosephosphate isomerase (tpi), and glutamate dehydrogenase (gdh) loci. Two assemblages were identified: potentially zoonotic assemblage A (54.2\%, 13/24) and rodent-specific assemblage $G(45.8 \%, 11 / 24)$. A total of 24,17 and 17 sequences of the $b g$, gdh and tpi loci, respectively, were successfully obtained, which formed four, four and three subtypes, respectively. Moreover, four assemblage A (MLGs A1-A4) and three assemblage G (MLGs G1-G3) multilocus genotypes were identified.

Conclusions: To our knowledge, this is the first study that investigated G. duodenalis in pet chipmunks in China. Detection of assemblage A in pet chipmunks and in previous studies in humans suggests a possible role of chipmunks as a reservoir for human giardiasis in Sichuan Province, China.
\end{abstract}

Keywords: Giardia duodenalis, Chipmunk, Assemblage, Multilocus genotype

\section{Background}

Giardia duodenalis is a common enteric parasite that infects a broad spectrum of vertebrate hosts, including humans, livestock, companion animals and wildlife worldwide [1]. Usually, humans and animals become infected with G. duodenalis via fecal-oral route by ingesting infective stage cysts in contaminated food or water [2]. Clinical manifestations vary depending upon the immunological status of the host [3]. In immunocompetent

\footnotetext{
* Correspondence: pgn.sicau@163.com

${ }^{\dagger}$ Equal contributors

The Key Laboratory of Animal Disease and Human Health of Sichuan Province, College of Veterinary Medicine, Sichuan Agricultural University, Chengdu, Sichuan Province 611130, China
}

individuals, G. duodenalis causes self-limiting diarrhea and malabsorption, whereas in infants, elderly persons, and individuals with deficient immune system, it also can cause chronic or life-threatening diarrhea and weight loss $[4,5]$.

Molecular studies have demonstrated that G. duodenalis comprises at least eight genetically distinct assemblages (A-H) [6]. Assemblages $\mathrm{A}$ and $\mathrm{B}$, considered zoonotic genotypes, can infect humans and a wide range of mammalian hosts, whereas the remaining assemblages (C-H) seem to be host-specific [7]. Assemblages $\mathrm{C}$ and D mainly infect dogs, assemblage E livestock, assemblage $\mathrm{F}$ cats, assemblage $\mathrm{G}$ rodents, and assemblage $\mathrm{H}$ marine 
mammals [8, 9]. So far, assemblages A and B have been determined as predominant genetic sub-populations of Giardia in pet rodents in countries such as Spain, Italy, Australia, Belgium and China [10-12]. In addition, assemblages $\mathrm{C}, \mathrm{G}$, and $\mathrm{E}$ have been also occasionally identified in pet rodents $[12,13]$.

In China, epidemiological data about Giardia prevalence have been reported in domestic dogs and cats (assemblages C and D) [14], raccoon dogs (assemblages $C$ and D) [15], cattle (A, B, and E) [16], horses (assemblages A and B) [17], sheep, goats (assemblages A, B and E) [18, 19], pet chinchillas (assemblages A and B) [11], as well as in humans (assemblages A and B) [20]. Recently, chipmunks (Eutamias asiaticus) have become popular in China as companion animals. As such, they have been commercially bred in significant numbers in many breeding facilities. However, information regarding $G$. duodenalis infection in pet chipmunks in China is rare, and the zoonotic potential of this parasite in chipmunks remains unknown. Therefore, the purpose of this study was to identify the prevalence and assemblages of G. duodenalis in pet chipmunks and to determine the genetic characteristics of G. duodenalis-positive samples.

\section{Methods}

\section{Specimen collection}

From March 2016 to April 2017, 279 fecal specimens were collected from chipmunks in seven pet shops and one breeding facility located in Sichuan province, southwestern China (Additional file 1: Table S1). Chipmunks were bred in individual cages. Fecal samples were collected from the bottom of the each cage, immediately placed into individual $30 \mathrm{ml}$ sterile containers, and taken to the laboratory in a cooler with ice packs within $24 \mathrm{~h}$. At sampling time, the age, sex, and health condition were recorded. All chipmunks whose fecal samples were examined were in apparently good health at the time of sampling.

\section{DNA extraction and PCR amplification}

All fecal specimens were washed three times by centrifugation at $1500 \times g$ for $10 \mathrm{~min}$ with distilled water. Genomic DNA was extracted from approximately 200 $\mathrm{mg}$ of each processed fecal specimen using an E.Z.N.A.R Stool DNA kit (Omega Biotek Inc., Norcross, GA, USA) according to the manufacturer's instructions. Extracted DNA was stored at $-20{ }^{\circ} \mathrm{C}$ until molecular analysis.

Giardia duodenalis prevalence and assemblages were first determined by nested PCR amplification of approximately $550 \mathrm{bp}$ fragment of the beta giardin $(\mathrm{bg})$ gene. Furthermore, $b g$-positive specimens were also analyzed by PCR amplification of the glutamate dehydrogenase $(g d h)$ and triosephosphate isomerase (tpi) genes. PCR amplification primers and annealing temperatures in this study (Table 1) were as previously reported [21]. PCR products were visualized by electrophoresis in $1.5 \%$ agarose containing ethidium bromide.

\section{Sequence and phylogenetic analyses}

All amplified products were sent to Life Technologies (Guangzhou, China) for sequencing on an ABI 3730 DNA Analyzer (Applied Biosystems, Foster City, CA, USA) using the BigDye ${ }^{\circ}$ Terminator v3.1 cycle sequencing kit. Nucleotide sequence accuracy was confirmed by sequencing two separate PCR products. Assemblages and subtypes were identified by aligning nucleotide sequences with known reference tpi, gdh and $b g$ gene sequences of $G$. duodenalis available in GenBank using BLAST (http://www.ncbi.nlm.nih.gov/BLAST/).

A phylogenetic analysis was performed by constructing a neighbor-joining tree using Mega 6 software [12], based on the evolutionary distances calculated by a

Table 1 Primer sequences, annealing temperatures and the fragment lengths of the genes used in this study

\begin{tabular}{|c|c|c|c|c|c|}
\hline Gene & Primer & Sequence $\left(5^{\prime}-3^{\prime}\right)$ & Annealing temperature $\left({ }^{\circ} \mathrm{C}\right)$ & Fragment length (bp) & Reference \\
\hline \multirow[t]{4}{*}{ bg } & F1 & AAGCCCGACGACCTCACCCGCAGTGC & 65 & 530 & [21] \\
\hline & R1 & GAGGCCGCCCTGGATCTTCGAGACGAC & & & \\
\hline & F2 & GAGGCCGCCCTGGATCTTCGAGACGAC & 65 & & \\
\hline & R2 & CATAACGACGCCATCGCGGCTCTCAGGAA & & & \\
\hline \multirow[t]{4}{*}{ tpi } & F1 & AAATIATGCCTGCTCGTCG & 50 & 530 & [21] \\
\hline & R1 & CAAACCTTITCCGCAAACC & & & \\
\hline & F2 & CCCTTCATCGGIGGTAACTT & 50 & & \\
\hline & R2 & GTGGCCACCACICCCGTGCC & & & \\
\hline \multirow[t]{4}{*}{$g d h$} & F1 & TTCCGTRTYCAGTACAACTC & 50 & 511 & [21] \\
\hline & R1 & ACCTCGTTCTGRGTGGCGCA & & & \\
\hline & F2 & ATGACYGAGCTYCAGAGGCACGT & 50 & & \\
\hline & R2 & GTGGCGCARGGCATGATGCA & & & \\
\hline
\end{tabular}


Kimura 2-parameter model. The reliability of these trees was assessed using bootstrap analysis with 1000 replicates.

\section{Results and discussion}

The present study identified 24 (8.6\%, 95\% CI: 0.053$0.119 \%)$ fecal samples that were G. duodenalis-positive by PCR analysis of the $b g$ gene. In China, the prevalence of giardiasis varies from $1.9 \%$ [22] to 27.1\% [11] in pets by PCRs. In Heilongjiang Province, the rates of infection with $G$. duodenalis in pet cats and dogs were 1.9 and $4.5 \%$, respectively [22]. In Guangzhou, $11 \%$ of fecal samples form pet dogs were positive for G. duodenalis [23]. The prevalence of G. duodenalis in pet dogs in Henan Province was $12.4 \%$ [14]. In Niaoning Province, the infection rate of $G$. duodenalis in farm dogs was $13.2 \%$ [24]. In Shanghai, Hualiu et al. [25] reported that G. duodenalis was found in 26.67 and $9.26 \%$ of samples from pets and zoo animals, respectively. The infection rate of $G$. duodenalis in pet chinchillas was $27.1 \%$ in four different cities in China [11]. The variability of G. duodenalis prevalence in China may be explained by the differences in geographical location, climate, age and gender of the animals, management system, and the diagnostic method.

The genetic diversity of G. duodenalis-positive samples was observed by sequencing the $b g$, tpi and $g d h$ genes. A total of 24, 17 and 17 sequences were obtained for the three gene loci, respectively (Table 2). Analysis of the $b g$ gene identified 13 sequences as belonging to assemblage A (9 subtype AI and 4 subtype AI-1) and 11 to assemblage G (7 subtype GI and 4 subtype GII). The subtype AI sequence (MF671918) was identical to the known assemblage AI sequences: accession no. KR051224 (from tortoise in China) and accession no. GQ329671 (from human in Sweden [26]). The subtype AI-1 sequence (MF671917) had one single nucleotide polymorphism (SNP) when compared to sequence KR051224 (Table 3). The subtype GI sequence (MF671919) was identical to sequence EU769221 (from Rattus norvegicus in Sweden), whereas the subtype GII sequence had two SNPs (at position $97 \mathrm{G} / \mathrm{A}$, and at position $325 \mathrm{~A} / \mathrm{C}$ ) in comparison with sequence EU769221. Among 17 samples positive for the tpi gene, 13 sequences were identified as assemblage A (5 subtype AI and 8 subtype AV) and 4 were identified as assemblage G (2 subtype GI and 2 subtype GII). The genetic characterization is presented in Table 3. Subtype GII sequence (MF671913) was identical to sequence EU781013 (from Rattus norvegicus in Sweden), whereas subtype GI sequence had one SNP (at position $184 \mathrm{C} / \mathrm{T})$ in comparison with sequence EU781013. Out of 17 samples positive for the $g d h$ gene, 10 sequences were identified as belonging to assemblage A (7 subtype AI and 3 novel subtypes AI-1) and 7 were identified as belonging to assemblage G. The novel subtype AI-1 sequence had not been reported previously; it had 5 SNPs when compared with sequence KR075940 (from sheep in China [27]) (Table 3). Assemblage G sequence was identical to sequence AY178748 (from mouse in Australia). The phylogenetic trees based on $b g, g d h$ and $t p i$ are presented in Additional file 2: Figure S1.

In the present study, assemblage A sequences were more prevalent than assemblage $G$ sequences, and no mixed assemblage $A$ and $G$ infections were detected. This result is consistent with data from previous studies in pets in China and Mexico [24, 28]. Thus far, assemblages $\mathrm{A}-\mathrm{C}, \mathrm{E}$ and $\mathrm{G}$ have been identified in rodents

Table 2 Assemblages of Giardia duodenalis and the distribution of bg, tpi and gdh sequences for each positive samples and multilocus characterization

\begin{tabular}{|c|c|c|c|c|c|}
\hline \multirow[t]{2}{*}{ Chipmunk ID } & \multicolumn{3}{|c|}{ Assemblage } & \multirow[t]{2}{*}{ GenBank ID } & \multirow{2}{*}{$\begin{array}{l}\text { MLG type } \\
(n)\end{array}$} \\
\hline & bg & tpi & gdh & & \\
\hline CD26, CD27 & $\mathrm{Gl}$ & $\mathrm{Gl}$ & G & MF671919, MF671914, MF671912 & MLG G1 (2) \\
\hline CD28 & Gl & Gll & G & MF671919, MF671913, MF671912 & MLG G2 (1) \\
\hline CD79 & GII & GII & G & MF671920, MF671913, MF671912 & MLG G3 (1) \\
\hline CD29, CD34, CD69 & $\mathrm{Al}$ & AV & Al-1 & MF671918, MF671915, MF671910 & MLG A1 (3) \\
\hline CD60, CD119 & $\mathrm{Al}$ & $\mathrm{Al}$ & $\mathrm{Al}$ & MF671918, MF671916, MF671911 & MLG A2 (2) \\
\hline CD61, CD96, CD124, CD144 & Al-1 & AV & $\mathrm{Al}$ & MF671917, MF671915, MF671911 & MLG A3 (4) \\
\hline CD64 & $\mathrm{Al}$ & AV & $\mathrm{Al}$ & MF671918, MF671915, MF671911 & MLG A4 (1) \\
\hline CD74, CD92, CD186 & $\mathrm{Al}$ & $\mathrm{Al}$ & Neg & MF671918, MF671916, - & - \\
\hline CD81, CD203, CD211 & Gll & Neg & Neg & MF671920, -, - & - \\
\hline CD22, CD44, CD102 & Gl & Neg & G & MF671919, -, MF671912 & - \\
\hline CD23 & Gl & Neg & Neg & MF671919, -, - & - \\
\hline
\end{tabular}


Table 3 Variations in the bg, tpi and gdh genes among Giardia duodenalis assemblage A isolates from chipmunks in Sichuan Province, southwestern China

\begin{tabular}{lllllllll}
\hline Subtype & GenBank & Gene & \multicolumn{7}{c}{ Nucleotide at position } \\
\cline { 3 - 9 } & & & ID & 248 & 275 & 287 & 443 & 469 \\
\hline Al (Ref.) & KR051224 & bg & A & A & C & A & A & T \\
Al & MF671918 & bg & A & A & C & A & A & T \\
Al-1 & MF671917 & bg & A & A & C & C & A & T \\
Al (Ref.) & EU014517 & tpi & C & A & A & A & C & G \\
Al & MF671916 & tpi & C & A & A & A & C & G \\
AV (Ref.) & KP780973 & tpi & C & T & C & G & A & T \\
AV & MF671915 & tpi & C & T & C & G & A & T \\
Al (Ref.) & KR075940 & gdh & C & T & G & G & C & A \\
Al & MF671911 & gdh & C & T & G & G & C & A \\
Al-1 & MF671910 & gdh & T & C & A & G & T & C \\
\hline
\end{tabular}

worldwide, and nearly all tested samples contained at least either assemblage A or B $[12,13]$. Subtyping assemblage A sequences at different loci has revealed three sub-assemblages: AI, AII, and AIII. In China, sub-assemblage AI has been detected in a variety of hosts, including humans, cattle, goat, sheep, dogs, cats and pigs [7]. Sub-assemblage AII has also been identified in humans in China. Cross-species transmission of G. duodenalis assemblage AI in Mexico and in Brazil has been recently reported [28, 29]. This finding suggests that chipmunks infected with assemblage AI were probably the source of human giardiasis due to frequent contact of the two species in that specific area. However, the generalization of this proposal requires systematic, molecular epidemiological investigations in humans and animals in other geographical areas. Recently, the multilocus genotype (MLG) model has been widely used to better understand the characteristics of $G$. duodenalis in different hosts and to assess its zoonotic potential [30, 31]. In this study, 14 samples were successfully sequenced at all three gene loci, and were characterized as four assemblage A MLGs and three different assemblage G MLGs (Table 2).

\section{Conclusions}

In the present study, for the first time, we described the rates of infection with $G$. duodenalis of pet chipmunks in Sichuan province of southwestern China and demonstrated the prevalence of assemblages A and G. On the basis of the multilocus sequence analysis, four assemblage A MLGs and three assemblage G MLGs were identified. Because assemblage A G. duodenalis is known to be zoonotic and has been identified in humans in China, pet chipmunks infected with assemblage A constitute a potential zoonotic risk to humans.

\section{Additional files}

Additional file 1: Table S1. Detailed information about each chipmunk (XLSX $20 \mathrm{~kb}$ )

Additional file 2: Figure S1. Phylogenetic relationships of Giardia duodenalis for the $b g$, tpi, and gdh loci (a, bg; b, tpi; c, gdh). The relationships between $G$. duodenalis genotypes identified in this study and other known genotypes deposited in GenBank were inferred by a neighbor-joining analysis of three genetic loci using the Kimura 2parameter model. Bootstrap values greater than 50\% from 1000 replicates are shown. Sequences obtained in this study are marked with a triangle. (TIFF 529 kb)

\section{Abbreviations}

bg: $\beta$-giardin; tpi: Triosephosphate isomerase; gdh: Glutamate dehydrogenase; MLGs: Multilocus genotype; SNP: Single nucleotide polymorphism

Acknowledgements

We would like to thank Qicheng Xiao and Rui Tu for collecting samples.

\section{Funding}

The study was supported financially by the National Science and Technology Department "13th five-year" Special Subproject of China (No.

2016YFD0501009) and the Chengdu Giant Panda Breeding Research Foundation (CPF2015-09; CPF2015-07).

\section{Availability of data and materials}

Representatives of all the nucleotide sequences generated in this study have been deposited in GenBank under the accession numbers MF671910MF671920.

\section{Authors' contributions}

GP and LD conceived and designed the experiments. RL, HL, YC, ZZ1 (Ziyao Zhou) and LY collected samples. Experiments were performed by LD, WW, HF, LL and ZZ2 (Zhijun Zhong), and the data were analyzed by LD, HF and SC. The manuscript was written by LD. All authors read and approved the final manuscript.

\section{Ethics approval}

The present study protocol was reviewed and approved by the Research Ethics Committee and the Animal Ethical Committee of Sichuan Agricultural University. Permission was obtained from the shop owners before the fecal specimens were collected.

Consent for publication

Not applicable.

\section{Competing interests}

The authors declare that they have no competing interests.

\section{Publisher's Note}

Springer Nature remains neutral with regard to jurisdictional claims in published maps and institutional affiliations.

Received: 27 November 2017 Accepted: 8 March 2018

Published online: 20 March 2018

\section{References}

1. Xiao L, Fayer R. Molecular characterisation of species and genotypes of Cryptosporidium and Giardia and assessment of zoonotic transmission. Int J Parasitol. 2008:38:1239-55.

2. Umapathy $G$, Mynářová $A$, Foitová I, Kváč $M$, Květoňová $D$, Rost $M$, et al. Prevalence of Cryptosporidium spp., Enterocytozoon bieneusi, Encephalitozoon spp. and Giardia duodenalis in wild, semi-wild and captive orangutans (Pongo abelii and Pongo pygmaeus) on Sumatra and Borneo, Indonesia. PLoS One. 2016;11:e0152771.

3. Robertson LJ, Hanevik K, Escobedo AA, Mørch K, Langeland N. Giardiasis why do the symptoms sometimes never stop? Trends Parasitol. 2010;26:75-82. 
4. Zaat JO, Mank TG, Assendelft WJA. systematic review on the treatment of giardiasis. Trop Med Int Health. 1998;47:63-82.

5. Berkman DS, Lescano AG, Gilman RH, Lopez SL, Black MM. Effects of stunting, diarrhoeal disease, and parasitic infection during infancy on cognition in late childhood: a follow-up study. Lancet. 2002;359:564-71.

6. Thompson RC, Ash A. Molecular epidemiology of Giardia and Cryptosporidium infections. Infect Genet Evol. 2016;40:315-323.

7. Feng Y, Xiao L. Zoonotic potential and molecular epidemiology of Giardia species and giardiasis. Clin Microbiol Rev. 2011;24:110-40.

8. Laseknesselquist E, Welch DM, Sogin ML. The identification of a new Giardia duodenalis assemblage in marine vertebrates and a preliminary analysis of $G$. duodenalis population biology in marine systems. Int J Parasitol. 2010:40:1063-74.

9. Monis PT, Caccio SM, Thompson RC. Variation in Giardia: towards a taxonomic revision of the genus. Trends Parasitol. 2009;25:93-100.

10. Veronesi F, Piergili FD, Morganti G, Bietta A, Moretta I, Moretti A, Traversa D. Occurrence of Giardia duodenalis infection in chinchillas (Chincilla lanigera) from Italian breeding facilities. Res Vet Sci. 2012;93:807-10.

11. Qi M, Yu F, Li S, Wang H, Luo N, Huang J, Zhang L. Multilocus genotyping of potentially zoonotic Giardia duodenalis in pet chinchillas (Chinchilla lanigera) in China. Vet Parasitol. 2015;208:113-7.

12. Levecke B, Meulemans L, Dalemans $T$, Casaert S, Claerebout E, Geurden T. Mixed Giardia duodenalis assemblage A, B, C and E infections in pet chinchillas (Chinchilla lanigera) in Flanders (Belgium). Vet Parasitol. 2011; 177:166-70

13. Fernándezálvarez Á, Martínalonso A, Abreuacosta N, Feliu C, Hugot JP, Valladares B, Foronda P. Identification of a novel assemblage $G$ subgenotype and a zoonotic assemblage B in rodent isolates of Giardia duodenalis in the Canary Islands, Spain. Parasitology. 2014;141:206-15.

14. Qi M, Dong H, Wang R, Li J, Zhao J, Zhang L, Luo J. Infection rate and genetic diversity of Giardia duodenalis in pet and stray dogs in Henan Province, China. Parasitol Int. 2016;65:159-62.

15. Zhang XX, Zheng WB, Ma JG, Yao QX, Zou Y, Bubu CJ, et al. Occurrence and multilocus genotyping of Giardia duodenalis assemblage $C$ and D in farmed raccoon dogs, Nyctereutes procyonoides, in China. Parasit Vectors. 2016;9:471.

16. Liu G, Su Y, Zhou M, Zhao J, Zhang T, Ahmad W, et al. Prevalence and molecular characterization of Giardia duodenalis isolates from dairy cattle in northeast China. Exp Parasitol. 2015;154:20-4.

17. Qi M, Zhou H, Wang H, Wang R, Xiao L, Arrowood MJ, et al. Molecular identification of Cryptosporidium spp. and Giardia duodenalis in grazing horses from Xinjiang, China. Vet Parasitol. 2015;209:169-72.

18. Peng $X Q$, Tian $G R$, Ren GJ, Yu ZQ, Lok JB, Zhang LX, et al. Infection rate of Giardia duodenalis, Cryptosporidium spp. and Enterocytozoon bieneusi in cashmere, dairy and meat goats in China. Infect Genet Evol. 2016; 41:26-31.

19. Zhang W, Zhang X, Wang R, Liu A, Shen Y, Ling H, et al. Genetic characterizations of Giardia duodenalis in sheep and goats in Heilongjiang Province, China and possibility of zoonotic transmission. PLoS Negl Trop Dis. 2012;6:e1826.

20. Wang R, Zhang X, Zhu H, Zhang L, Feng Y, Jian F, et al. Genetic characterizations of Cryptosporidium spp. and Giardia duodenalis in humans in Henan, China. Exp Parasitol. 2011;127:42-5.

21. Cacciò SM, Beck R, Lalle M, Marinculic A, Pozio E. Multilocus genotyping of Giardia duodenalis reveals striking differences between assemblages $A$ and B. Int J Parasitol. 2008;38:1523-31

22. Li W, Li Y, Song M, Lu Y, Yang J, Tao W, et al. Prevalence and genetic characteristics of Cryptosporidium, Enterocytozoon bieneusi and Giardia duodenalis in cats and dogs in Heilongjiang Province, China. Vet Parasitol. 2015;208(34):125.

23. Li J, Zhang P, Wang P, Alsarakibi M, Zhu H, Liu Y, et al. Genotype identification and prevalence of Giardia duodenalis in pet dogs of Guangzhou, southern China. Vet Parasitol. 2012;188:368-71.

24. Li W, Liu C, Yu Y, Li J, Gong P, Song M, et al. Molecular characterization of Giardia duodenalis isolates from police and farm dogs in China. Exp Parasitol. 2013;135:223-6.

25. Liu H, Shen Y, Liu A, Yin J, Yuan Z, Jiang Y, et al. Occurrence and multilocus genotyping of Giardia duodenalis in pets and zoo animals in Shanghai, China. J Infet Dev Ctries. 2017:11:479-86.

26. Lebbad M, Petersson I, Karlsson L, Botero-Kleiven S, Andersson JO, Bo S, Svärd SG. Multilocus genotyping of human Giardia isolates suggests limited zoonotic transmission and association between assemblage $B$ and flatulence in children. PLoS Negl Trop Dis. 2011;5:e1262.

27. Ye J, Xiao L, Wang Y, Guo Y, Roellig DM, Feng Y. Dominance of Giardia duodenalis assemblage A and Enterocytozoon bieneusi genotype BEB6 in sheep in Inner Mongolia, China. Vet Parasitol. 2015;210:235-9.

28. Garcíacervantes PC, Báezflores ME, Delgadovargas F, Poncemacotela M, Nawa Y, Delacruzotero MD, et al. Giardia duodenalis genotypes among schoolchildren and their families and pets in urban and rural areas of Sinaloa, Mexico. J Infect Dev Ctries. 2017;11:180-7.

29. Coelho $\mathrm{CH}$, Durigan M, Leal DAG, Schneider ADB, Franco RMB, Singer SM. Giardiasis as a neglected disease in Brazil: Systematic review of 20 years of publications. PloS Negl Trop Dis. 2017;11:e0006005.

30. Meng Q, Wang H, Bo J, Wang R, Jian F, Ning C, et al. Prevalence and multilocus genotyping of Giardia duodenalis in dairy calves in Xinjiang, northwestern China. Parasit Vectors. 2016:9:546.

31. Zhang XX, Tan QD, Zhao GH, Ma JG, Zheng WB, Ni XT, et al. Prevalence, risk factors and multilocus genotyping of Giardia duodenalis in dairy cattle, northwest China. J Eukaryot Microbiol. 2016;63:498-504.

\section{Submit your next manuscript to BioMed Central and we will help you at every step:}

- We accept pre-submission inquiries

- Our selector tool helps you to find the most relevant journal

- We provide round the clock customer support

- Convenient online submission

- Thorough peer review

- Inclusion in PubMed and all major indexing services

- Maximum visibility for your research

Submit your manuscript at www.biomedcentral.com/submit
C) Biomed Central 